\title{
The Merged Department Experience at Utah State University: Is Diversity a Blessing or a Curse?
}

Larry A. Rupp

Summary. The Plants, Soils, and Biometeorology Department at Utah State University was formed in 1989 as the result of a merger between the Soil Science and Biometeorology Department and the Plant Science Department. While constant vigilance is required to keep the department balanced and functioning as a single unit, overall the combined department seems to be stronger than the previous units.

The Plants, Soils, and Biometeorology Department (PSB) at Utah State University is a merged department consisting of

faculty from what would be traditionally described as horticulture, crop science, soils, and biometeorology departments. The department is housed within the College of Agriculture and each of these discipline groups has a long and distinguished history within the college. They also have a complex lineage of interactions with each other over the history of the College of Agriculture. Only recently have they all been combined into one department. This merger has resulted in both positive and negative results.

\section{History of the Plants, Soils, and Biometeorology Department}

The College of Agriculture at Utah State University was founded in 1890, as the Utah Agricultural College. By 1911, there were departments of horticulture and agronomy as well as others. This structure continued with minor modifications until 1965 when the Plant Science Department was organized which included all of horticulture and all field crop functions previously included in the Agronomy Department. At the same time the Soil Science and Biometeorology Department was created. In 1989 the Plant Science Department and the Soil Science and Biometeorology Department were merged to form the PSB. 
Formation of the PSB was not based on popular faculty sentiment. Rather, the combination was created under the direction of the Dean of the College of Agriculture and coincided with retirements in both departments. At the time of the merger, the existing department heads stepped down in light of impending retirements and a new head was appointed from outside the university.

Concurrent with the changes in departments within the College of Agriculture were changes in demographics within the state of Utah. By 1990, Utah, which had been a heavily agricultural state, had become a place where only $1.6 \%$ of total personal income came from farming and $78 \%$ of the population lived in the four most urban counties along the Wasatch Front (Utah Governor's Office of Planning and Budget, 2000). These changes in the demographics of the state undoubtedly contributed to a change in undergraduate student populations as well. All degree programs were retained, but undergraduate student numbers in horticulture have far outgrown the numbers in the other departmental degree programs of crop science and environmental soil and water science (Fig. 1).

While undergraduate student numbers have changed dramatically with the demographics of the state, research and extension programs have been less affected. Funding for research projects has remained strong within traditional commodity-based and discipline-based research programs. While undergraduate enrollment is high in horticulture, grant funding for horticulture faculty has consistently been lower than the other disciplines within the department (Fig. 2). Graduate student numbers have more closely reflected the funding base with more students in crop science and soil science and fewer students in horticulture and biometeorology. Currently, the department consists of ten faculty in crop science, eight in soils, seven in horticulture, and five in biometeorology (Fig. 3).

Simply stated, the existing departments were merged to capitalize on an apparent synergy that could result from their combination. The Soils and Biometeorology Department had strong research and extension programs, but a limited number of students. The horticulture portion of the Plant Science Department had a growing undergraduate student population, but a limited research program. When combined into a new department, the strengths and weaknesses of the previous departments complemented each other and resulted in a single department that overall was much stronger. The difficulty in combining the departments has been in trying to get a very diverse group to function as one department rather than several minidepartments.

Several advantages exist in the new configuration, including the following:

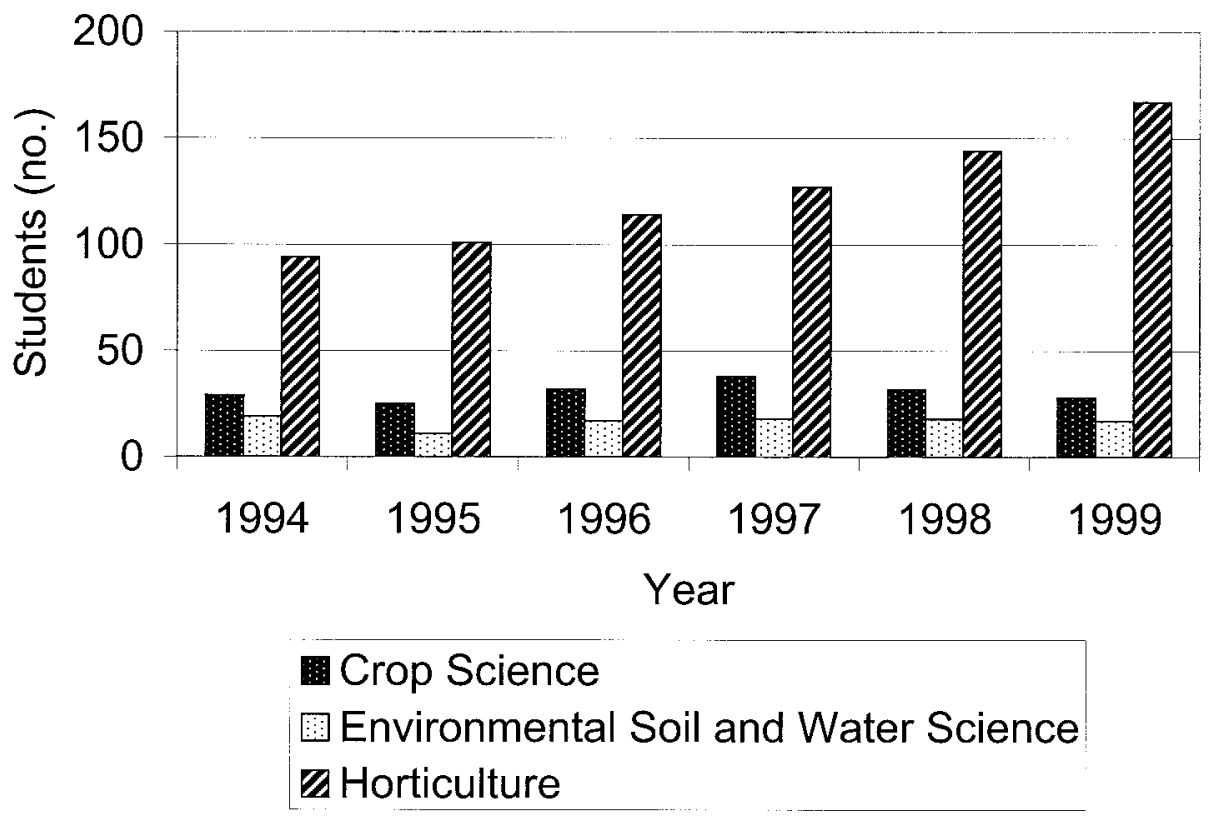

Fig. 1. Numbers of undergraduate students enrolled in the Plants, Soils, and Biometeorology Department (1994-99).

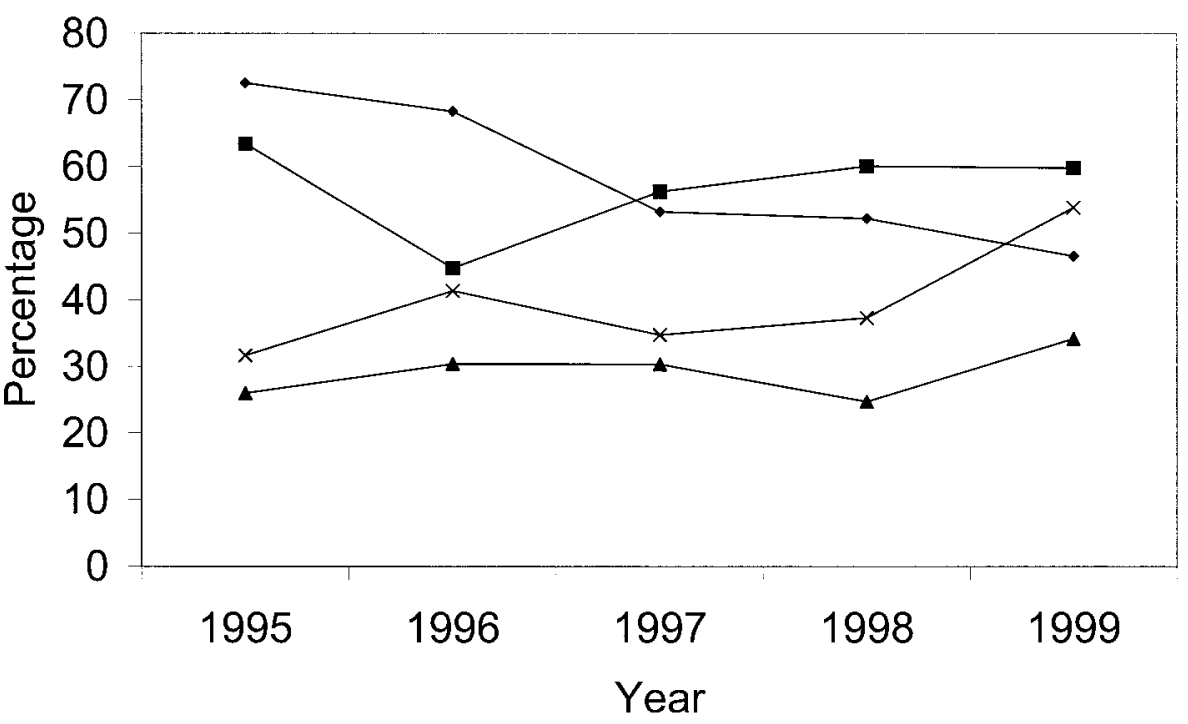

$\rightarrow$ Agronomy - Biometeorology $\rightarrow$ Horticulture $*$ Soils

Fig. 2. Expended extramural grant funds as a percentage of total funding within discipline groups of agronomy, biometeorology, horticulture, and soils, as administered by the Utah Agricultural Experiment Station. 
ing disciplines interact more frequently, thus providing more opportunity for cooperative projects and solutions to problems.

- Minimized redundancy. As currently established the department has a good balance between critical mass and redundancy in faculty disciplines. There are enough faculty in most areas to complement each other, but not so many that turf battles result.

Unfortunately, just as there are advantages to a combined department, there are also disadvantages. These disadvantages include the following:

- Problems with minidepartments. One of the biggest issues is that crop science and horticulture tend to be based around commodities, while soil science and biometeorology are based more around a scientific discipline. This leads to fundamental differences in philosophy and approaches to concerns common to the whole department. As concerns are faced, it is easy to retreat to a comfort zone within the common philosophy of one's peers. Sometimes this minidepartment configuration is unavoidable. For example, with degree programs in horticulture it is critical that the horticulturists work together on teaching and curriculum. There is not much opportunity to bring others into these programs in a meaningful fashion.

- Difficulty in reaching consensus. The great diversity of the faculty and missions can make it difficult to reach consensus on issues within the department. This is especially the case if minidepartments develop.

- It is easy to misunderstand the strengths and weaknesses of individual faculty members. Sometimes the differences in backgrounds are so great that faculty simply do not understand each other. Other times a lack of appreciation is found for the effort put into teaching or research because it may be outside an individual's area of expertise.

- Perception can be a false reality. It is possible in a diverse department for faculty members to develop a bit of paranoia that the "other" groups are trying to take all of the resources. In the PSB experience, I would say that this is mostly unfounded and that very rarely are faculty directly trying to take resources from a colleague's program for use in their own.

- Limited depth in specialties. The nature of a combined department is such that most faculty are the only one working in their area of specialty. While there may be good cross-disciplinary support, it can be frustrating not to have colleagues working with the same commodities or issues.

I believe that it is possible to make diversity within a department an advantage. I think several things can be done in this regard:

- Avoid minidepartments. It is very easy to fall back into these comfort zones and a constant effort must be made to work as a single department and not to recognize or inad-

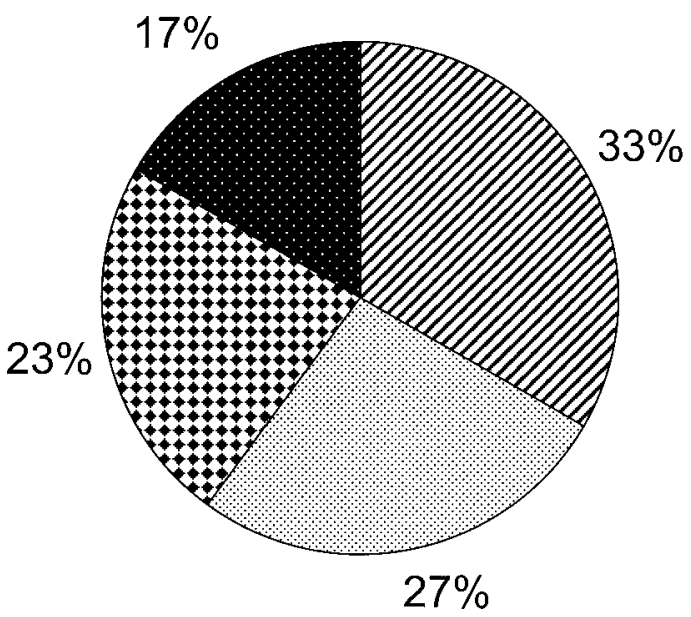

Fig. 3. Distribution of Plants, Soils, and Biometeorology Department faculty among discipline groups of crop science, soil science, horticulture, and biometeorology.

vertently foster smaller segments.

- Communicate. Communication is absolutely critical so that everyone has an idea as to what is happening across the department. Communication also reduces the paranoia about what other programs are doing.

- Encourage and reward collaboration. The greatest benefit of diverse departments is the potential for collaboration. Such collaboration should be both fostered and rewarded.

- Equal recognition of scholarship. Scholarship must be defined and recognized equally using a model such as that delineated by Conrad Weiser (Weiser, 1997). Diversity within the department is so great that it is critical that faculty be judged according to their role statement, and that scholarship be rewarded equally whether it be through teaching, research, or extension.

- Administration must have a department-wide perspective and be able to share that vision with the members of the department. Perhaps most critical to this issue is that the department administration must be fair. The definition of fairness as implying an "elimination of one's own feelings, prejudices, and desires so as to achieve a proper balance of conflicting interests" (Gove, 1972 ) illustrates the importance of this concept.

The combined PSB at Utah State University has created a dynamic and vibrant working environment. Overall, it has been positive for the department, while requiring constant nurturing and vigilance to keep it balanced and moving in a positive direction.

\section{Literature cited}

Gove, P.B. (ed.). 1972. Webster's seventh new collegiate dictionary. G. and C. Merriam, Springfield, Mass.

Utah Governor's Office of Planning and Budget. 2000. Economic report to the Governor. Utah Governor's Office of Planning and Budget, Salt Lake City.

Weiser, C.J. 1997. Faculty scholarship and productivity expectations - An administrator's perspective. HortScience 32:37-39. 